\title{
Biosorption of Malathion from Aqueous Solutions Using Herbal Leaves Powder
}

\author{
Tharakeswar Yadamari, Kalyan Yakkala, Gangadhar Battala, Ramakrishna Naidu Gurijala* \\ Department of Environmental Sciences, Sri Venkateswara University, Tirupati, India \\ E-mail: "naidugrk@yahoo.com \\ Received October 2, 2011; revised November 8, 2011; accepted November 16, 2011
}

\begin{abstract}
Commonly available herbal leaves powder namely Achyranthes aspera (uthareni) and Phyllanthus niruri (Nela usiri) are used as biosorbents for the removal of malathion in the present investigation. The efficiency of the biosorbents is tested for the determination of malathion using batch experiments under controlled conditions as a function of $\mathrm{pH}$, contact time, initial malation concentration and the optimization amount of biosorbents. The quantification of malathion in aqueous samples, before and after equilibration with biosorbents is carried out by existing spectrophotometric method based on the oxidation of malathion with excess N-bromosuccinimide (NBS) and Rhodamine $B$ at $\left(\lambda_{\max }=550 \mathrm{~nm}\right)$ is used for the unconsumed NBS. The biosorption capacities are found to be $\mathrm{pH}$ dependent. The maximum adsorption is noticed at $\mathrm{pH}=6$ with a contact time of 120 minutes. Biosorption equilibrium isotherms are plotted for malathion uptake capacity $\left(Q_{e}\right)$ against residual malathion concentration $\left(C_{e}\right)$ in solution. The $Q_{e}$ versus $C_{e}$ sorption isotherms relationship is expressed mathematically by Langmuir and Freundlich models. The removal of malathion using biosorbents Achyranthes aspera (uthareni) and Phyllanthus niruri (Nela usiri) from spiked river water samples are found to be $94 \%$ and $96 \%$ respectively. The developed eco-friendly potential biosorbents indicate that the present method can be successfully applied for the quantitative determination and removal of malathion from real water samples.
\end{abstract}

Keywords: Biosorption, Malathion, Achyranthes aspera (Uthareni) and Phyllanthus niruri (Nela usiri), Isotherm Models

\section{Introduction}

Natural water is contaminated with various pesticides and their transformation products. Pesticides are potential contaminants of natural water because they are directly applied to the soil and are transported into ground water or leached to the surface water [1-5]. The rapid use of pesticides for high yielding of crops has unfortunately generated many environmental problems. As a result, human beings are exposed indirectly to pesticides in trace amounts through various foodstuffs [6]. Patients of acute organophosphorus poisoning have been reported to suffer from problems like vomiting, nausea, excessive salivation, blurred vision, headache, giddiness etc. [7]. Malathion shown in Scheme 1 is one of the widely used organophousphours pesticide which is used to kill insects on agricultural crops, on stored products, in home gardens and in outdoor sites. The various effects observed by malathion exposure are due to its active metabolite malaxon on various organs of organisms [8]. Numerous malathion poisoning incidents have taken place among pesticides workers and small children through accidental exposure. Wide range of toxic effects of malathion is observed in various organisms [9]. Malathion is rapidly and effectively absorbed practically by all routs, including the gastrointestinal tract, skin, mucous membranes and lungs. Removal of malathion from natural water has been important concern due to its toxic and hazardous

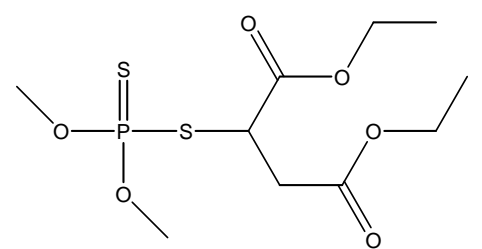

Scheme 1. Chemical structure of malathion. 
behavior. The various adsorbents are used for the removal of pesticides in water samples includes-Activated carbon [10-15], straw [16], Lignocellulosic substrate from agro industry [17], baggasse fly ash [18], coal fly ash [19], Charcoal from agro waste [20] and bark [21]. Biosorption is one of the effective alternative methods for the removal of pesticides in contaminated water samples. Biosorption has been used as an alternative technology for removing toxic pollutants in water samples [22]. In addition to scientific preference, economic considerations also play crucial role in the selection of appropriate biomass for pollution abatement. Thus intense research attention is now focused on cost effective, ecofriendly and easily available adsorbent particularly of biological origin [23]. However, the performance of a biosorbent depends on the characteristic properties of the biomass as well as the microenvironment of the target toxicant. The search for an appropriate and inexpensive biomass is a continuing process. The most effective and optimized utilization of a biomass demands a detailed understanding of the binding mechanism. The adsorption of malathion is monitored by various researchers using biomaterials such as Rhizopus oryzae biomass by Subhankar Chatterjee et al. [23], bagasse fly ash by Gupta et al. [24], thermally treated egg shell by Khalid Z. Elwakeel et al. [25] and Waste Jute Fiber Carbon by Senthilkumaar et al. [26]. In the present study, commonly available herbal leaves powder namely Achyranthes aspera (uthareni) and Phyllanthus niruri (Nela usiri) is used as a biosorbents for the removal of malathion from real water samples.

\section{Experimental}

\subsection{Apparatus}

Measurements are performed with a UV-visible spectrophotometer model UV-1800 from Shimadzu, (Japan) for recording the absorbance spectra. A LI-120 digital $\mathrm{pH}$ meter (Elico, India) is used for the $\mathrm{pH}$ measurement, weighing of the reagents and chemicals are carried with Shimadzu AUX 320 digital electronic balance. IR spectrometer (Thermo-Nicolet FT-IR, Nicolet IR-200, USA) is used for functional groups analysis of the biomass.

\subsection{Reagents and Solution}

All the reagents used in this study are of analytical grade, malathion is obtained from Hyderabad Chemicals Ltd, India. Double distilled water is used through out the present work. N-Bromosuccinimide is obtained from Sigma Aldrich, USA. Rhodamine B is obtained from Sd. Fine. Chem. Pvt. Ltd., India. Hydrochloric acid and Glacial acetic acid are obtained from Merck., India.

Malathion stock solution $1000 \mu \mathrm{g} \cdot \mathrm{mL}^{-1}$ is prepared by using $0.813 \mu \mathrm{L}$ of technical grade malathion (95.5\%) and dissolved in a little amount of glacial acetic acid and made up to the mark with deionised double distilled water to a $100 \mathrm{~mL}$ volumetric flask. N-Bromosuccinimide w/v (0.01\%), and Rhodamine B w/v (0.02\%) are used for the present studies.

\subsection{Preparation of Biosorbent Materials}

Leaves of Achyranthes aspera (uthareni) and Phyllanthus niruri (Nela usiri) are collected and washed several times and dried in shadow. Dried leaves are grounded and sieved to $50 \mu \mathrm{cm}$ size mesh. Sieved leaves powder is washed with deionised double distilled water and then dried. To avoid the release of colour from the leaves powder in to the aqueous solution during adsorption it is treated with formaldehyde. For this $5 \mathrm{~mL}$ of aqueous formaldehyde is added to $100 \mathrm{~mL} 0.1 \mathrm{M} \mathrm{H}_{2} \mathrm{SO}_{4}$ and then $10 \mathrm{~g}$ of washed leaves powder is added to this solution. The final mixture is stirred and heated at $50^{\circ} \mathrm{C}$ for $24-48$ hours till the mixture became thick slurry. The slurry is washed with deionised distilled water and then dried. The prepared biomass was then stored in air tight glass bottles to be protected from moisture. The prepared biosorbent is used in the further studies.

\subsection{Malathion Measurement Procedure}

An aliquot of sample solution containing $0.3-1.8$ $\mu \mathrm{g} \cdot \mathrm{mL}^{-1}$ is transferred into a series of $25 \mathrm{~mL}$ calibrated flask. To this $1.5 \mathrm{~mL}$ of NBS, $1 \mathrm{~mL}$ of glacial acetic acid and $0.5 \mathrm{~mL}$ of hydrochloric acid are added successively. The solution is kept aside with occasional shaking for about $10 \mathrm{~min}$ at $\sim 30^{\circ} \mathrm{C}$. Then $0.7 \mathrm{~mL}$ of rhodamine $\mathrm{B}$ solution is added and mixed thoroughly. The absorbance is measured against distilled water at $558 \mathrm{~nm}$. The decrease in absorbance corresponding to consumed oxidant by subtracting the decrease in absorbance of the test solution (dye minus test) from that of the blank solution (dye minus blank). Calibration graph is prepared by plotting the decrease in absorbance of dye against amount of the pesticide [27].

\subsection{Fourier Transformed Infrared Spectroscopic (FTIR) Analysis}

FTIR spectra of powdered Achyranthes aspera (uthareni) and Phyllanthus niruri (Nela usiri) biomass have been recorded on IR spectrometer (Thermo-Nicolet FT-IR, Nicolet IR-200, USA). Pressed pellets are prepared by grinding the samples with $\mathrm{KBr}$ in a mortar and immedi- 
ately analyzed in the region of $4000-400 \mathrm{~cm}^{-1}$.

\subsection{Batch Adsorption Studies}

The affinity of biomass to adsorb malathion is studied in batch experiments. In all sets of experiments, fixed volume of malathion solution $(25 \mathrm{~mL})$ is stirred with desired biosorbent dose (50 - $125 \mathrm{mg}$ ) for the period of two hours. Different conditions of $\mathrm{pH}(3-8)$, initial concentrations $\left(0.3-1.8 \mu \mathrm{g} \cdot \mathrm{mL}^{-1}\right)$ and contact time (30 - 150 minutes) are evaluated during study. In order to regulate $\mathrm{pH}$ of the medium $0.1 \mathrm{~N}$ of $\mathrm{HCI}$ and $\mathrm{NaOH}$ are used. The solutions are separated from biomass by filtration through whatman 40 filter paper. Malathion concentration in the filtrate is estimated using UV spectrophometer at $558 \mathrm{~nm}$ wave length by following the procedure prescribed above.

The amount of malathion adsorbed in $\mathrm{mg} \cdot \mathrm{g}^{-1}$ at time is computed by using the following equation.

$$
Q_{e}=\frac{\left(C_{i}-C_{e}\right) V}{m}
$$

where:

$Q_{e}$ is the malathion concentration adsorbed (mg malathion concentration/g biosorbent) at equilidrium,

$V$ is the volume of the solution $(L)$,

$C_{i}$ and $C_{e}$ are the initial and equilibrium concentration of malathion (mg/L) and $\mathrm{m}$ is the dry weight of the biosorbent (g).

the percentage of the removal of malathion concentration $\left(R_{e m} \%\right)$ in solution was calculated using the equation:

$$
R_{e m}(\%)=\frac{\left(C_{i}-C_{e}\right)}{C_{i}} \times 100
$$

where $C_{i}$ and $C_{e}$ are the initial and the equilibrium concentration of malathion $\left(\mu \mathrm{g} \cdot \mathrm{mL}^{-1}\right)$.

\subsection{Adsorption Isotherm Models}

An adsorption is a quantitative relationship describing the equilibrium between the concentrations of absorbate in solution (mass/volume) and their concentration (mass adsorbate/mass adsorbent).

An adsorption isotherms relate to the concentration of solute on the surface of the adsorbent to the concentration of the solute in the fluid where the adsorbent is in contact. These values are usually determined experimentally. In order to describe the equilibrium isotherm of biosorption process, Langmuir and Freundlich isotherm models are discussed in the present experiment.

\subsubsection{Langmuir Isotherm Model}

The Langmuir isotherm model is based on the following assumptions:

- $\quad$ Each active site interact with only one adsorbate molecule,

- $\quad$ Sorbate molecules are adsorbed on well localized sites,

- $\quad$ There is no interaction between adjacent adsorbed molecules, and

- $\quad$ The adsorption sites are all energetically equivalent. Langmuir isotherm is given by the following equation:

$$
Q_{e}=\frac{K_{L} Q_{\max } C_{e}}{1+K_{L} C_{e}}
$$

where $Q_{e}$ is the equilibrium malathion concentration on the adsorbent (mg/g),

$C_{e}$ is the equilibrium malathion concentration in the solution (mg/g),

$Q_{\max }$ is the maximum biosorption capacity of adsorbent (mg/g) and

$K_{L}$ is the Langmuir biosorption constant ( $\left.\mathrm{L} / \mathrm{mg}\right)$. Langmuir isotherm equation can be represented by the following linear form;

$$
\frac{C_{e}}{Q_{e}}=\frac{1}{K_{L} Q_{\max }}+\frac{C_{e}}{Q_{\max }}
$$

The values of Langmuir constant $Q_{\max }$ and $K_{L}$ are calculated from the slope and intercept of the linear plot $C_{e} / Q_{e}$ versus $C_{e}$. The essential feature of Langmuir isotherm model can be expressed by means of a separation factor of equilibrium parameter $\left(R_{L}\right)$, which is calculated according to the following equation;

$$
R_{L}=\frac{1}{1+K_{L} C_{i}}
$$

The values of $R_{L}$ indicates the type of biosorption isotherm to be:

- $\quad$ Linear $\left(R_{L}=1\right)$,

- $\quad$ Favorable $\left(0<R_{L}<1\right)$,

- Unfavorable $\left(R_{L}>1\right)$ and

- $\quad$ Irreversible $\left(R_{L}=0\right)$.

\subsubsection{Freundlich Isotherm Model}

The Freundlich isotherm model is derived from Gibbs adsorption combined with a mathematical description of the free energy of the surface. Freundlich proposed an empirical isotherm equation assuming a heterogeneous adsorption surface and active sites with different energy. The Freundlich equation is as follows:

$$
Q_{e}=K_{f} C_{e}^{1 / n}
$$

The Freundlich isotherm can be derived from Langmuir isotherm by assuming that there exists a distribution of sites on the adsorbent which have different affinities 
for different adsorbetes with each site behaving according to Langmuir isotherm. Here, $K_{f}$ is a measure of the capacity of the adsorbent and " $n$ " is a measure of how affinity for the adsorbate changes with the change in adsorption density.

when $n=1$, the Freundlich isotherm becomes linear isotherm and indicates that all sites on the adsorbent have equal affinity for the adsorbates. Values of $n>1$ indicate the affinities decrease with increasing adsorption density. The linear form of Freundlich isotherm equation can be shown as;

$$
\log C_{e}=\log K_{f}+\frac{1}{n} \log C_{e}
$$

The Freundlich isotherm constants $1 / n$ and $K_{f}$ are calculated from the slopes and intercepts of the linear plot of $\log Q_{e}$ versus $\log C_{e}$.

\subsection{Application to Real Water Samples}

The developed biosorbents are used for the removal of malathion in the river water samples which are collected in and around Tirupati. To $20 \mathrm{~mL}$ of sample, a known amount of malathion $\left(1.2 \mu \mathrm{g} \cdot \mathrm{mL}^{-1}\right)$ is spiked and the aqueous samples are adjusted to $\mathrm{pH}=6$ by adding 100 mg of biosorbent and with a continuous stirring for 120 minutes. After adsorption, malathion is determined in filtrate by UV-Vis Spectrophotometer followed by the procedure prescribed above.

\section{Results and Discussion}

Efficiency of the biosorbents (herbal leaves powder) is tested for the removal of malathion in natural water. The rate of adsorption is a function of the initial concentration of malathion which makes it an important factor to be considered for effective biosorption. The factors like effect of $\mathrm{pH}$, contact time, dosage of biosorbent etc., on malathion sorption capacity of herbal leaves powder are investigated. All the experiments are repeated thrice to confirm the results and average values are presented.

\subsection{Fourier Transformed Infrared Spectroscopic (FTIR) Analysis}

FTIR spectra of powdered Achyranthes aspera (uthareni) and Phyllanthus niruri (Nela usiri) biomass for malathion adsorption are shown in Figures 1 and 2. As can be seen from the [Figure 1], the vibration bands at 3288.82 $\mathrm{cm}^{-1}, 1635.92 \mathrm{~cm}^{-1}, 2922.3 \mathrm{~cm}^{-1}, 1518.17 \mathrm{~cm}^{-1}$ are due

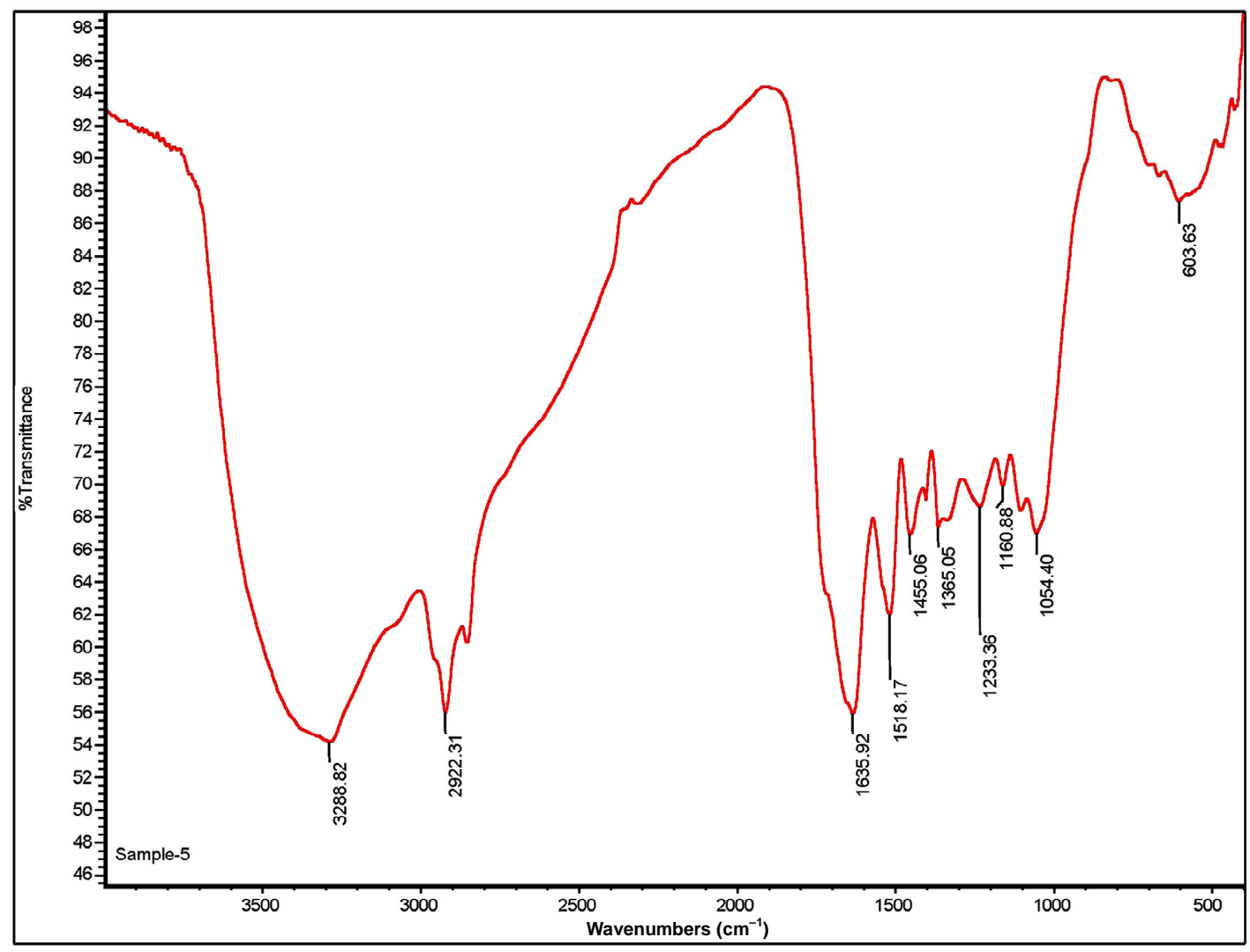

Figure 1. FTIR spectrum of Achyranthes aspera (uthareni) leaves powder. 
to the presence of hydroxyl group, Carbonyl $(\mathrm{C}=\mathrm{O})$, and presence of vinyl stretch $\mathrm{C}-\mathrm{H}, \mathrm{C}-\mathrm{N}$ stretching vibrations. As in the [Figure 2], the vibrations are due to the presence of stretch C-H, C-N stretching vibrations.

\subsection{Effect of pH}

$\mathrm{pH}$ is an important parameter that influences the adsorption process by way of modifying the functional groups of the biomass. The effect of $\mathrm{pH}$ on adsorption of malathion is conducted in the $\mathrm{pH}$ range of 3.0 - 8.0. Adsorption of malathion by two biosorbents Achyranthes aspera (uthareni) and Phyllanthus niruri (Nela usiri) is found to increase only to a small extent with increase in $\mathrm{pH}$ values from 3.0 - 6.0 and then decreased with increase in $\mathrm{pH}$ i.e. from 6.0 - 8.0. After tests with both biosorbents Phyllanthus niruri is removing the malathion effectively at a percentage of 96, where as Achyranthes aspera is removing the malathion at a percentage of 94 at $\mathrm{pH}$ 6.0. the $\mathrm{pH}$ studies for both the sorbents is shown in the [Figure 3].

\subsection{Effect of Contact Time}

The equilibrium time required for the adsorption of malathion on both the biosorbents with $1.2 \mu \mathrm{g} \cdot \mathrm{mL}^{-1}$ of malathion is tested at different time intervals are also studied [Figure 4]. It is shown that adsorption capacity sharply increased with the increased in time and attained equilibrium in 120 minutes for both the biosorbents Phyllanthus niruri leaves powder (Nela usiri) and Achyranthes aspera (uthareni) leaves powder. The removal rate of malathion increases with the increase of the adsorption time. However, it remains constant after an equilibrium time of 120 minutes, which indicates that the adsorption tends towards saturation. Therefore, the adsorption time is set 120 minutes in each of the experiment. The rate of adsorption is higher in the beginning due to large surface area available of the biosorbent. After the capacity of the adsorbent gets exhausted, i.e. at equilibrium, the rate of uptake is controlled by the rate at which the absorbate is transported from the exterior to the interior sites of the biosorbent particles [28].

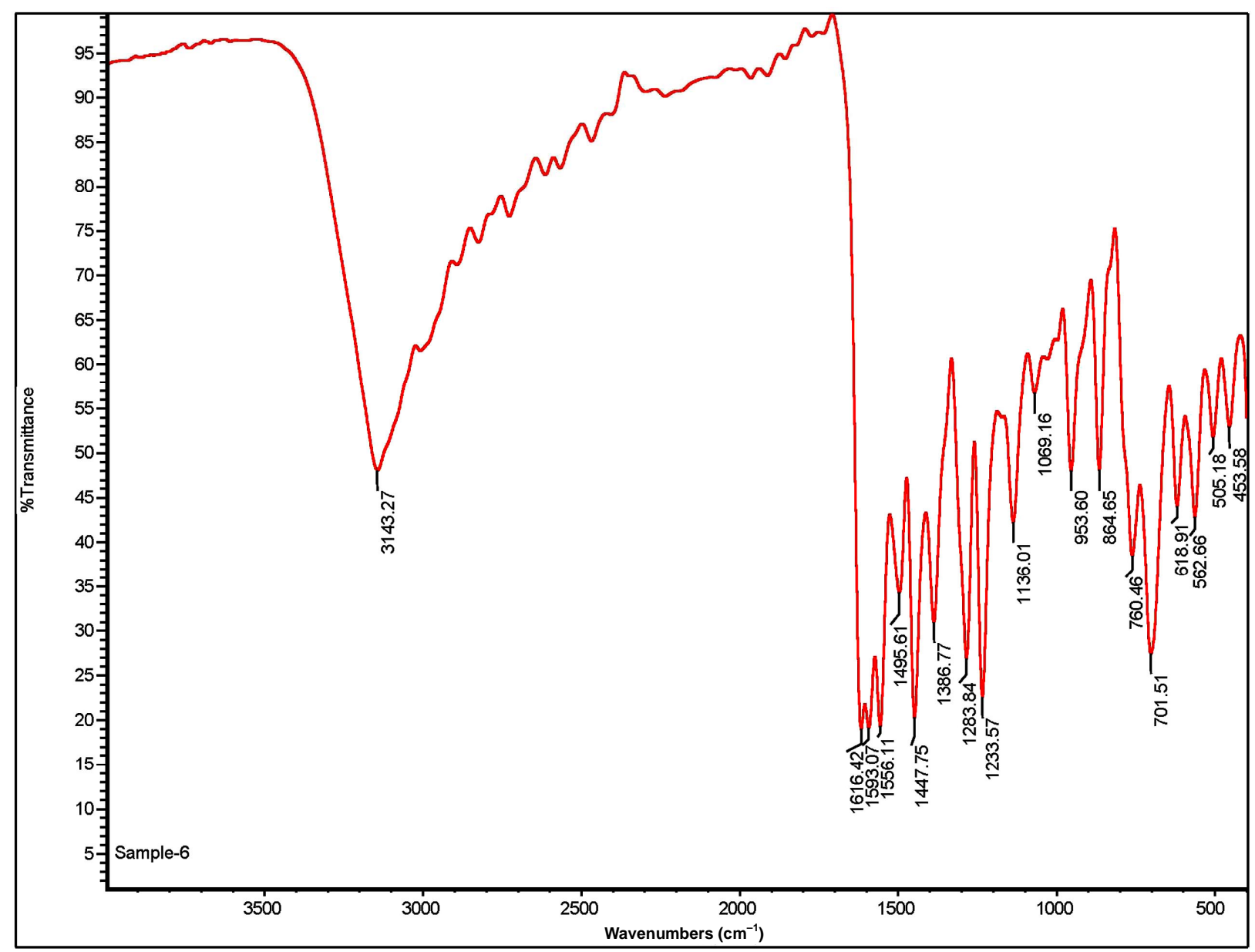

Figure 2. FTIR spectrum of Phyllanthus niruri (Nela usiri) leaves powder. 


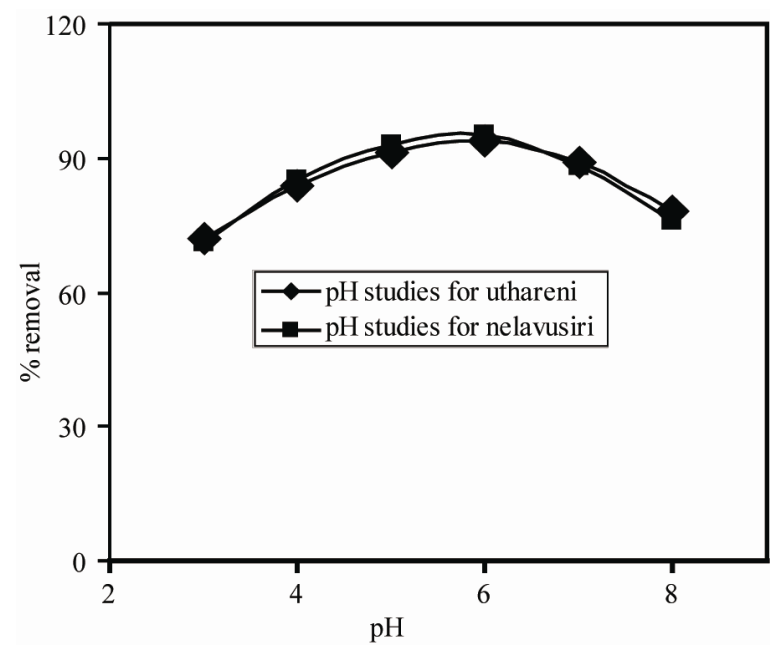

Figure 3. Effect of pH for adsorption of malathion on biosorbents (Achyranthes aspera (uthareni) leaves powder and Phyllanthus niruri leaves powder (Nela usiri)).

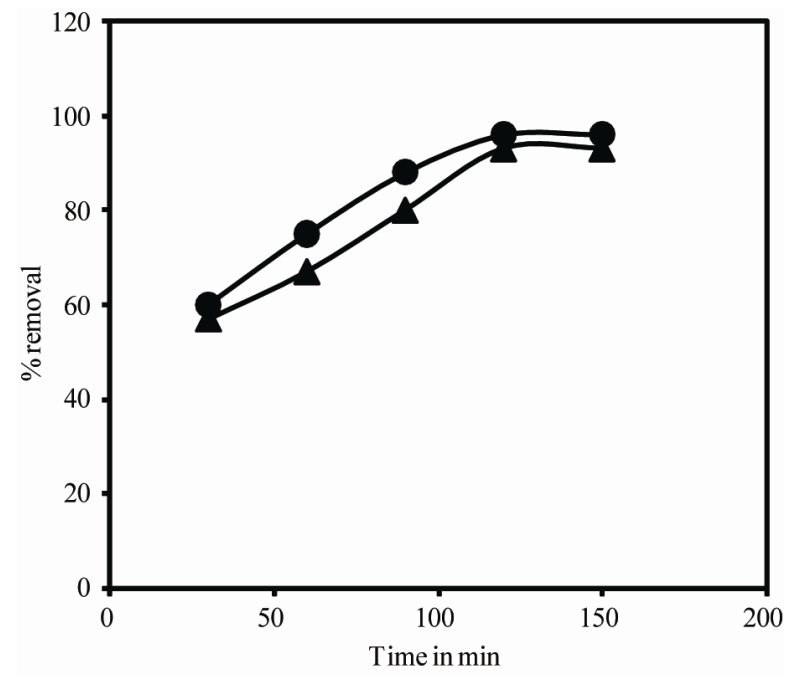

Figure 4. Effect of time for adsorption of malathion on biosorbents (Achyranthes aspera (uthareni) leaves powder and Phyllanthus niruri leaves powder (Nela usiri)).

\subsection{Effect of Biomass Dosage}

The effect of biosorbent dosage on the removal of malathion is shown in [Figure 5], the amount of biosorbent is varied from $25 \mathrm{mg}-125 \mathrm{mg}$ and equilibrated for 120 minutes with the concentration of $1.2 \mu \mathrm{g} \cdot \mathrm{mL}^{-1}$. The results indicated that the percent removal of malathion increased with the increase in the amount of adsorbent and the efficiency of removal for Achyranthes aspera (uthareni) leaves powder and Phyllanthus niruri leaves powder (Nela usiri) are $94 \%$ and $96 \%$ respectively. The highest uptake yield is obtained at biosorbent concentration of $100 \mathrm{mg}$ for the both the sorbents. The removal of

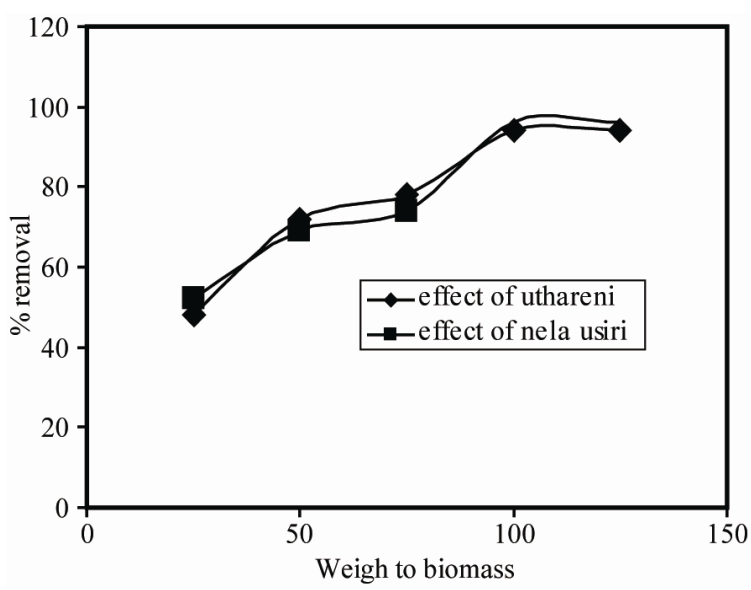

Figure 5. Effect of biomass dosage for adsorption of malathion on biosorbents (Achyranthes aspera (uthareni) leaves powder and Phyllanthus niruri leaves powder (Nela usiri)).

malathion concentration increased with the increase in biosorbent concentration and attained equilibrium after $100 \mathrm{mg}$ of adsorbent dosage for malathion. This is due to the availability of more biosorbent as well as greater availability of surface area [29].

\subsection{Adsorption Isotherms}

The Langmuir and Freundlich isotherm models are used to describe the biosorption equilibrium of selected herbal leaves powder. It is also helpful in comparing different biomaterials under the same operational conditions. To find the relationship between aqueous concentration $\left(C_{e}\right)$ and sorbed quantity $\left(Q_{e}\right)$ at equilibrium, mostly isotherms models are used for fitting the data. The $\mathrm{C}_{e}$ and $Q_{e}$ values for both the biosorbents during the study of malathion extraction is shown in the [Tables 1 and 2]. Langmuir parameters can be determined from a linearized form of equation given below.

$$
\frac{C_{e}}{Q_{e}}=\frac{1}{K_{L} \cdot Q_{\max }}+\frac{C_{e}}{Q_{\max }}
$$

The values of the Langmuir constants $\left(K_{L}, Q_{\max }\right)$ and Freundlich constants $(K, n)$ are presented for the biosorption of malathion by Achyranthes aspera (uthareni) leaves powder and Phyllanthus niruri leaves powder (Nela usiri) is shown in [Table 3]. It shows that the $\mathrm{R}^{2}$ value for Langmuir isotherm and Freundlich isotherm is similar to both the biosorbents. [Figures 6 and 7] show that Langmuir isotherm model of malathion for Achyranthes aspera (uthareni) leaves powder and Phyllanthus niruri leaves powder (Nela usiri) with $\mathrm{R}^{2}$ of 0.9907 and 0.986. [Figures 8 and 9] show that Freundlich isotherm model of malathion for Achyranthes aspera (uthareni) 
Table 1. Aqueous concentration $\left(C_{e}\right)$ and sorbed quantity $\left(Q_{e}\right)$ at equilibrium for malathion by Achyranthes aspera (uthareni).

\begin{tabular}{cccccc}
\hline$C_{i}$ & $C_{e}$ & $Q_{e}$ & $C_{e} / Q_{e}$ & $\log C_{e}$ & $\log Q_{e}$ \\
\hline 0.5 & 0.028 & 0.118 & 0.237 & -1.55 & -0.92 \\
0.9 & 0.052 & 0.212 & 0.245 & -1.28 & -0.67 \\
1.2 & 0.071 & 0.282 & 0.251 & -1.14 & -0.54 \\
1.5 & 0.090 & 0.352 & 0.255 & -1.04 & -0.45 \\
\hline
\end{tabular}

Table 2. Aqueous concentration $\left(C_{e}\right)$ and sorbed quantity $\left(Q_{e}\right)$ at equilibrium for malathion by Phyllanthus niruri (Nela usiri).

\begin{tabular}{cccccc}
\hline$C_{i}$ & $C_{e}$ & $Q_{e}$ & $C_{e} / Q_{e}$ & $\log C_{e}$ & $\log Q_{e}$ \\
\hline 0.5 & 0.019 & 0.12 & 0.158 & -1.72 & -0.92 \\
0.9 & 0.035 & 0.216 & 0.166 & -1.45 & -0.66 \\
1.2 & 0.049 & 0.287 & 0.170 & -1.30 & -0.54 \\
1.5 & 0.063 & 0.359 & 0.175 & -1.20 & -0.44 \\
\hline
\end{tabular}

Table 3. Linear regression data for Langmuir and Freundlich isotherms for malathion biosorption.

\begin{tabular}{cccccccc}
\hline \multirow{2}{*}{ S. No. } & \multirow{2}{*}{ Biomass } & \multicolumn{3}{c}{ Langumuir parameters } & \multicolumn{4}{c}{ Freundlich parameters } \\
\cline { 3 - 7 } & & $Q_{\max }(\mathrm{mg} / \mathrm{g})$ & $\mathrm{K}_{\mathrm{L}}(\mathrm{L} / \mathrm{mg})$ & $\mathrm{R}^{2}$ & $\mathrm{~N}$ & $\mathrm{~K}_{\mathrm{f}}$ & $\mathrm{R}^{2}$ \\
\hline 1 & Achyranthes aspera (uthareni) & 3.401 & 1.28 & 0.9907 & 1.1005 & 0.4905 & 0.9994 \\
2 & Phyllanthus niruri (Nela usiri) & 2.644 & 2.4 & 0.986 & 1.0930 & 0.6569 & 0.9987 \\
\hline
\end{tabular}

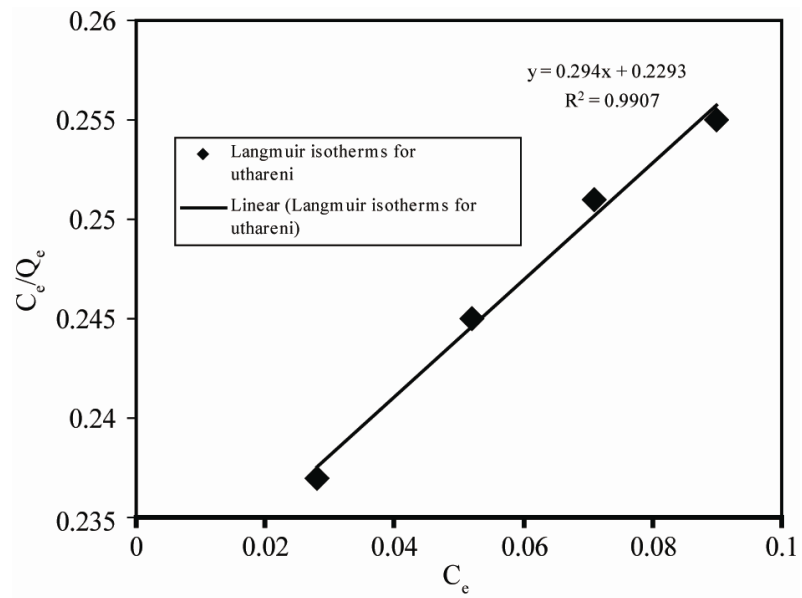

Figure 6. Langmuir isotherm model for adsorption of malathion by Achyranthes aspera (uthareni) as biosorbent.

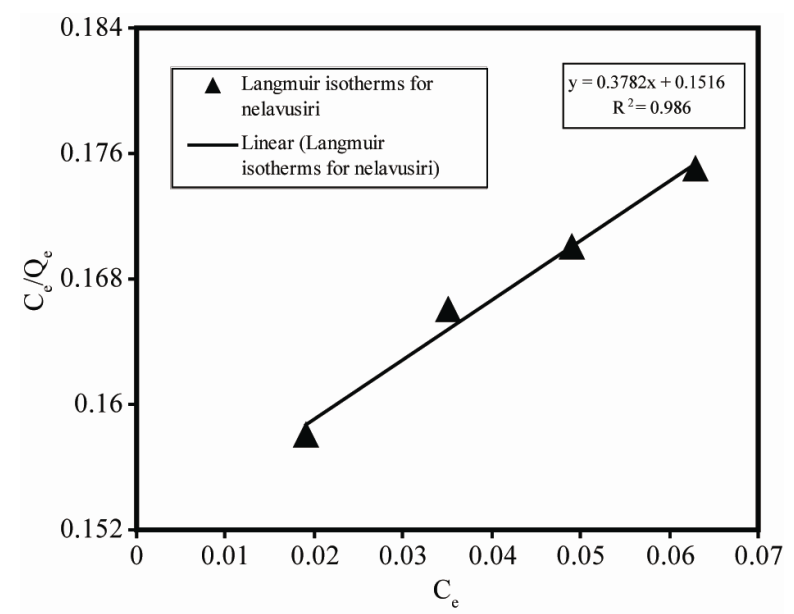

Figure 7. Langmuir isotherm model for adsorption of malathion by Phyllanthus niruri (Nela usiri) as biosorbent.

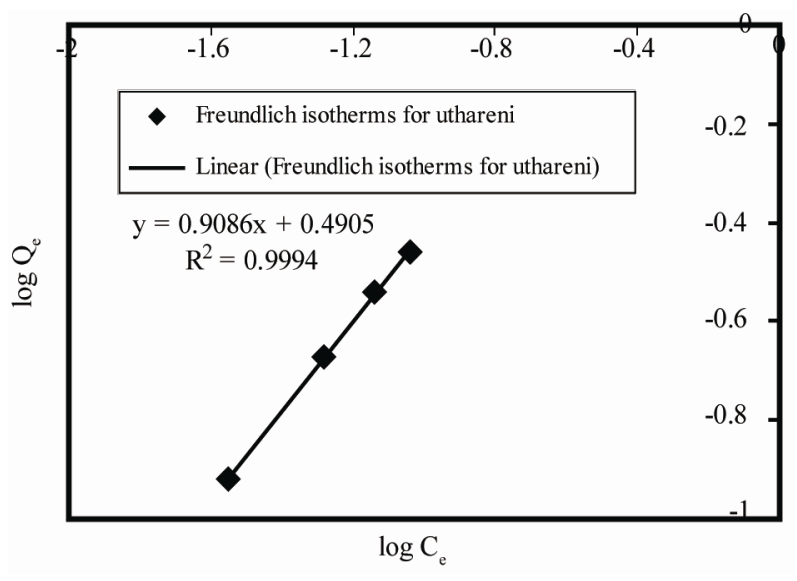

Figure 8. Freundlich isotherm model for adsorption of malathion by Achyranthes aspera (uthareni) as biosorbent.

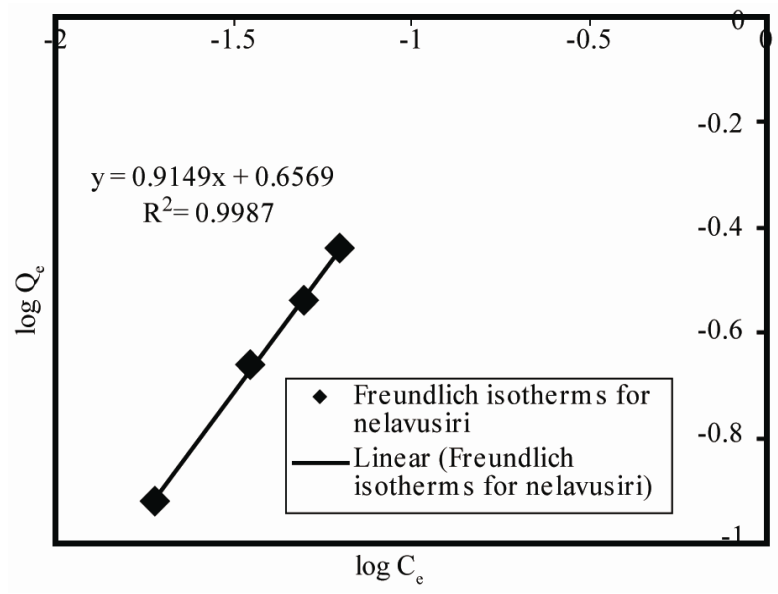

Figure 9. Freundlich isotherm model for adsorption of malathion by Phyllanthus niruri (Nela usiri) as biosorbent. 
Table 4. Recovery percentage of malathion by using biosorbents from the river water samples.

\begin{tabular}{|c|c|c|c|c|c|c|}
\hline \multirow[b]{2}{*}{ Sample } & \multicolumn{3}{|c|}{ Achyranthes aspera (uthareni) } & \multicolumn{3}{|c|}{ Phyllanthus niruri (Nela usiri) } \\
\hline & $\begin{array}{c}\text { Malathion spiked in } \\
\mu \mathrm{g} \cdot \mathrm{mL}^{-1}\end{array}$ & $\begin{array}{c}\text { Malathion found in } \\
\mu \mathrm{g} \cdot \mathrm{mL}^{-1}\end{array}$ & Recovery \% & $\begin{array}{c}\text { Malathion spiked in } \\
\mu \mathrm{g} \cdot \mathrm{mL}^{-1}\end{array}$ & $\begin{array}{c}\text { Malathion found in } \\
\mu \mathrm{g} \cdot \mathrm{mL}^{-1}\end{array}$ & Recovery \% \\
\hline River water-1 & 1.2 & $1.13 \% \pm 1.3 \%$ & 94 & 1.2 & $1.154 \% \pm 1.2 \%$ & 96 \\
\hline River water-2 & 1.2 & $1.135 \% \pm 1.5 \%$ & 95 & 1.2 & $1.153 \% \pm 1.4 \%$ & 96 \\
\hline
\end{tabular}

leaves powder and Phyllanthus niruri leaves powder (Nela usiri) with $\mathrm{R}^{2}$ of 0.9994 and 0.9987.

The Langmuir constants $\left(Q_{\max }\right)$ are found to be 3.401 \& 2.644 for both the biosorbents, while $K_{L}$ which reflects quantitatively the affinity between the adsorbent and adsorbate is equal to $1.28 \& 2.4 \mathrm{~L} / \mathrm{mg}$ for both biosorbents.

The Freundlich model is expressed as:

$$
Q_{e}=K_{f} C_{e}^{1 / n}
$$

The above equation can be rearranged in the following form:

$$
\log Q_{e}=\log K_{f}+\frac{1}{n} \log C_{e}
$$

$Q_{e}$ is malation sorbed (mg/g). $C_{e}$ the equilibrium concentration of malathion solution $(\mathrm{mg} / \mathrm{L}), K_{f}$ and $N$ are Freundlich constants. The constants $K_{f}$ and $1 / n$ is used as an indication of whether adsorption remains constant (at $1 / n=1$ ) or decreases with increasing adsorbate concentrations. It appears from the [Figures 8 and 9] that Freundlich model best fits the experimental results which are similar to Langmuir [Figures 6 and 7] over the experimental range with good correlation co-efficient. The $\mathrm{n}$ value and $\mathrm{K}_{f}$ values are found to be as $1.1005,1.0930$ and $0.4905,0.6569$ for both the biosorbents.

Finally, the developed biosorbents are used for the analysis of river water samples which are collected in and around Tirupati by spiking with constant amount of malathion. As shown in Table 4, the recovery percentage of malathion using developed biosorbents Achyranthes aspera (uthareni) and Phyllanthus niruri (Nela usiri) is found to be $94 \%$ and $96 \%$ respectively.

\section{Conclusions}

The selected biosorbents namely Achyranthes aspera (uthareni) and Phyllanthus niruri (Nela usiri) are found to be potential sorbents for the removal of malathion from aqueous solutions. The adsorption of malathion is $\mathrm{pH}$ dependent and its adsorption capacity increased with increasing the $\mathrm{pH}$ up to 6 and it decreased with further increase of $\mathrm{pH}>6$. The developed biosorbents used to remove the malathion effectively from aqueous solutions in the concentration range of $\left(0.3-1.5 \mu \mathrm{g} \cdot \mathrm{mL}^{-1}\right)$. Langmuir-Freundlich isotherm models fit for the adsorption of malathion and its recovery $>95 \%$ indicated that the functional groups present in the biosorbents are mainly responsible for chemical interaction between malathion and biosorbent cell walls. The two developed ecofriendly biosorbents Achyranthes aspera (uthareni) and Phyllanthus niruri (Nela usiri) have been successfully applied for the removal of malathion in spiked river water samples.

\section{References}

[1] S. Hatrfk and J. Tekel, "Extraction Methodology and Chromatography for the Determination of Residual Pesticides in Water," Journal of Chromatography A, Vol. 733, No. 1-2, 1996, pp. 217-233. doi:10.1016/0021-9673(95)00725-3

[2] J. Thomas, L. T. Ou and A. All-Agely, "DDE Remediation and Degradation," Reviews of Environmental Contamination \& Toxicology, Vol. 194, 2008, pp. 55-69. doi:10.1007/978-0-387-74816-0_3

[3] P. C. Abhilash and N. Singh, "Pesticide Use and Application: An Indian Scenario,” Journal of hazardous materials, Vol. 165, No. 1-3, 2009, pp.1-12. doi:10.1016/j.jhazmat.2008.10.061

[4] M. J. Perry, S. A. Venners, D. B. Barr and X. Xu, "Environmental Pyrethriod and Organophosphours Insecticide Exposure and Sperm Concentration,” Reprod Toxicology, Vol. 23, No. 1, 2007, pp. 113-118. doi:10.1016/j.reprotox.2006.08.005

[5] M. Bhanti and A. Taneja, "Contamination of Vegetables of Different Seasons with Organophosphorous Pesticides and Related Health Risk Assessment in Northern India," Chemosphers, Vol. 69, No. 1, 2007, pp. 63-68. doi:10.1016/j.chemosphere.2007.04.071

[6] X.-G. Chu, X. Z. Hu and H.-Y. Yao, "Determination of 266 Pesticide Residues in Apple Juice by Matrix Solid-Phase Dispersion and Gas Chromatography-Mass Selective Detection,” Journal of Chromatography A, Vol. 1063, No. 1-2, 2005, pp. 201-210. doi:10.1016/j.chroma.2004.12.003

[7] S. B. Agrawal, “A Clinical Biochemical Neurobehavioral and Sociopsychological Study of 190 Patients Admitted to Hosopital as Result of acute Organophosphorus Poisoning,” Environmental Research, Vol. 62, No. 1, 1993, pp. 63-67. doi:10.1006/enrs.1993.1089 
[8] E. Vilanova and M. A. Sogorb, "The Role of Phosphotriesters in the Detoxification of Organophosphorus Compounds," Critical Review in Toxicology, Vol. 29, 1999, pp. 21-57. doi:10.1080/10408449991349177

[9] C. J. Wang and Z. Q. Liu, "Foliar Uptake of Pesticide-Present Status and Future Challenge," Pesticide Biochemistry and Physiology, Vol. 87, No. 1, 2007, pp. 1-8. doi:10.1016/j.pestbp.2006.04.004

[10] K. Ohno, T. Minami, Y. Matsui and Y. magara, "Effect of Chlorine on Organophosphorus Pesticides Adsorbed on Activated Carbon: Desorption and Oxon Formation,” Water Research, Vol. 42, No. 6-7, 2008, pp. 1753-1759.

[11] B. H. Hameed, J. M. Salman and A. L. Ahmad, “Adsorption Isotherm and Kinetic Modeling of 2,4-D Pesticide on Activation Derived from Date Stones," Journal of Hazardous Materials, Vol. 163, No. 1, 2009, pp. 121-126. doi:10.1016/j.jhazmat.2008.06.069

[12] D. C. Adams and L. T. Watson, "Treatability of S-Triazine Herbicide Metabolites Using Powdered Activated Carbon," Journal of Environmental Engineering, Vol. 122, No. 4, 1996, pp. 327-330. doi:10.1061/(ASCE)0733-9372(1996)122:4(327)

[13] H. Jiang, C. Adams, N. Grazino, A. Roberson, M. Macguire and D. Khiari, "Occurance and Removal of Chloro -S-Triazine in Water Treatment Plants," Environmental Science and Technology, Vol. 40, No. 11, 2006, pp. 36093613. doi:10.1021/es052038n

[14] M. V. Lopez-Ramon, M. A. Fontecha-Camara, M. A. Alvarez-Merino and C. Moreno-Castilla, "Removal of Diuron and Amitrol from Water under Static and Dynamic Conditions Using Activated Carbon in Form of Fiber, Cloth and Grains,” Water Research, Vol. 41, No. 13, 2007, pp. 2865-2870. doi:10.1016/j.watres.2007.02.059

[15] C. S. Castro, M. C. Guerreiro, M. Gonclaves, L. C. Oliveira and A. S. Anastacio, "Activited Carbon/Iron Oxide Composites for the Removal of Atrizane from Aqueous Medium," Journal of Hazardous Materials, Vol. 164, No. 2-3, 2009, pp. 609-614. doi:10.1016/j.jhazmat.2008.08.066

[16] M. Akhtar, S. M. Hasany, M. I. Bhanger and S. Iqbal, "Low Cost Sorbent for the Removal of Methyl Parathion Pesticide from Aqueous Solution,” Chemosphere, Vol. 66, No. 10, 2007, pp.1829-1838. doi:10.1016/j.chemosphere.2006.09.006

[17] H. E. Bakouri, J. Morillo, J. Usero and A. Quassini, "Natural Attention of Pesticide Water Contamination by Using Ecological Adsorbents: Application for Chlorinated Pesticides Included in European Water Frame Work Directives,” Journal of Hydrology, Vol. 364, No. 1-2, 2009, pp. 175-181. doi:10.1016/j.jhydrol.2008.10.012

[18] U. Traub-Eberhard, K. P. Hensche, W. Kordel and W. Klein, "Influence of Different Field Sites on Pesticide Movement into Subsurface Drain,” Pesticide Science,
Vol. 43, No. 2, 1995, pp. 121-129. doi:10.1002/ps.2780430205

[19] N. Singh, "Adsorption of Herbicides on Coal Fly Ash from Aqueous Solutions,” Journal of Hazardous Materials, Vol. 168, No. 1, 2009, pp. 233-237. doi:10.1016/j.jhazmat.2009.02.016

[20] Y. Sudhakar and A. K. Dikshit, “Adsorbent Selection for Endosulfan Removal from Waste Water Environment," Journal of Environmental Science and Health, Part B, Vol. 34, No. 1, 1999, pp. 97-118. doi:10.1080/03601239909373186

[21] S. Boudesocque, E. Guillon, M. Aplincourt, F. Martel and S. Noael, "Use of a Low Cost Biosorbent to Remove Pesticides from Waste Water," Journal of Environmental Quality, Vol. 37, No. 2, 2008, pp. 631-638. doi:10.2134/jeq2007.0332

[22] S. Schiewer and B. Volesky, "Ionic Strength and Electrostatic Effects in Biosorption and Protons," Environmental Science and Technology, Vol. 31, No. 7, 1997, pp.18631871. doi:10.1021/es960434n

[23] S. Chatterjee, S. K. Das, R. Chakravarthy, A. Chakrabarti, S. Ghosh and A. K. Guha, "Interactive of Malathion, an Organophosphorus Pesticide with Rhizopus oryzea Biomass," Journal of Hazardous Materials, Vol. 174, No. 1-3, 2010, pp.47-53. doi:10.1016/j.jhazmat.2009.09.014

[24] V. K. Gupta, C. K. Jain, I. Ali, S. Chandra and S. Agarwal, "Removal of Lindane and Malathion from Wastewater Using Bagasse Fly Ash-A Sugar Industry Waste,” Water Research, Vol. 36, No. 10, pp. 2483-2490.

[25] K. Z. Elwakeel and A. M. Yousif, "Adsorption of Malathion on Thermally Treated Egg Shell Material," Fourteenth International Water Technology Conference, Cairo, Egypt, 2010, pp. 53-65.

[26] A. Sunita, C. Parimal and R. Lalitagauri, "Biosorption of Malathion by Immobilized Cells of Bacillus sp. S14," Chemical Speciation and Bioavailability, Vol. 22, No. 4, 2010, pp. 271-276.

[27] S. B. Mathew, A. K. Pillai and V. K. Gupta, “A Rapid Spectrophotometric Assay of Some Organophosphorus Pesticide Residues in Vegetable Samples," Spectrochimica Acta Part A, Vol. 67, No. 5, 2007, pp.1430-1432. doi:10.1016/j.saa.2006.11.020

[28] A. Verma, S. Chakraborty and J. K. Basu, “Adsorption Study of Hexavalent Chromium Using Tramarind HullBased Adsorbents, Separation and Purification Technology,” Vol. 50, No. 3, 2006, pp. 336-341. doi:10.1016/j.seppur.2005.12.007

[29] M. Aoyama, "Removal of Cr (VI) from Aqueous Solution by London Plane Leaves," Journal of Chemical Technology and Biotechnology, Vol. 78, No. 5, 2003, pp. 601-604. doi:10.1002/jctb.838 